\title{
BMJ Open Magnitude of optimal adherence and predictors for a low level of adherence among HIV/AIDS-infected adults in South Gondar zone, Northwest Ethiopia: a multifacility cross- sectional study
}

\author{
Shimeles Biru Zewude (D) ,' Tewodros Magegnet Ajebe ${ }^{2}$
}

To cite: Zewude SB, Ajebe TM. Magnitude of optimal adherence and predictors for a low level of adherence among HIV/ AIDS-infected adults in South Gondar zone, Northwest Ethiopia: a multifacility crosssectional study. BMJ Open 2022;12:e056009. doi:10.1136/ bmjopen-2021-056009

- Prepublication history for this paper is available online. To view these files, please visit the journal online (http://dx.doi. org/10.1136/bmjopen-2021056009).

Received 02 August 2021 Accepted 02 December 2021

D) Check for updates

(c) Author(s) (or their employer(s)) 2022. Re-use permitted under CC BY-NC. No commercial re-use. See rights and permissions. Published by BMJ.

${ }^{1}$ Department of Midwifery, College of Health Sciences, Debre Tabor University, Debre Tabor, Ethiopia

${ }^{2}$ Department of Midwifery, College Of Medicine and Health Sciences, Wollo University, Dessie, Ethiopia

Correspondence to Shimeles Biru Zewude; shimeles.biru@yahoo.com

\section{ABSTRACT}

Objectives This study aims to identify levels of adherence to antiretroviral therapy (ART) drugs and factors associated with them in Northwest Ethiopia. We hypothesise that in the era of COVID-19, there would be suboptimal adherence to ART drugs.

Design An observational cross-sectional study was conducted. Factors associated with the level of adherence were selected for multiple logistic regressions at a $\mathrm{p}$ value of less than 0.2 in the analysis. Statistically significant associated factors were identified at a p value less than 0.05 and adjusted OR with a $95 \% \mathrm{Cl}$.

Setting The study was conducted in one specialised hospital and three district hospitals found in the South Gondar zone, Northwest Ethiopia.

Participants About 432 people living with HIV/AIDS receiving highly active ART in South Gondar zone public hospitals and who have been on treatment for more than a 3-month period participated in the study.

Primary and secondary outcome measures Levels of adherence to ART drugs and their associated factors.

Results Among 432 study participants, 81.5\% (95\% Cl: $78 \%$ to $85.2 \%$ ) of participants were optimally adherent to ART drugs. Determinants of a low level of adherence: stigma or discrimination $(\mathrm{OR}=0.4, \mathrm{p}=0.016)$, missed scheduled clinical visit $(O R=0.45, p=0.034)$, being on tuberculosis treatment $(0 R=0.45, p=0.01)$, recent $C D 4$ cell count less than 500 cells $/ \mathrm{mm}^{3}(\mathrm{OR}=0.3, p=0.023)$ and patients who had been on WHO clinical stage III at the time of $A R T$ initiation $(O R=0.24, p=0.027)$ were factors significantly associated with adherence to ART drugs. Conclusions Level of adherence was relatively low compared with some local studies. The intervention targeted to reduce discrimination, counselling before initiation of treatment and awareness regarding compliance is advised to improve adherence to antiretroviral regimens.

\section{INTRODUCTION}

HIV/AIDS is one of the pandemic public health problems still affecting many people.
Strengths and limitations of this study

There is a possibility of recall bias and social desirability bias.

- Findings are also generalisable only for patients treated as outpatients.

- Being a cross-sectional survey, causality cannot be inferred from those findings.

- Adherence level is a snapshot of adherence behaviour during COVID-19 infection.

- The present study has a strength due to the use of robust data collection tools that ensured the quality of the study.

At the end of 2020, 37.7 million people globally were living with HIV. In the same year, 1.5 million people were newly infected by the virus and 680000 people died from AIDS-related illnesses. ${ }^{1}$ Countries are taking different actions to tackle the HIV/AIDS epidemic as well as to improve the quality of life among people infected by the virus; one of these was the treatment of patients with antiretroviral therapy (ART). ${ }^{2}$

In Ethiopia, achieving optimal adherence and sustainable follow-up in care and treatment are the most difficult in HIV/AIDS management. A 5-year retrospective medical record review of 3012 adult patients who were enrolled in therapy at Gondar University Hospital ART clinic demonstrated that $31.4 \%$ of patients had been lost to follow-up. ${ }^{3}$

Highly active ART (HAART) involves sophisticated regimens that necessitate careful adherence to intricate treatment schedules owing to the high risk of developing treatment-resistant forms of HIV as a result of missing, underdosing and irregular use of antiretroviral drugs. ${ }^{4}$ 
Adherence to multidrug antiretroviral regimens has been a focus of attention since ART drugs' introduction owing to their complexity, frequent adverse effects and chronic nature. ${ }^{56}$

To get optimal viral suppression and prevent treatment failure, individuals should take more than $95 \%$ of prescribed drugs. If once the individual fails to take more than $95 \%$ of prescribed drugs, the virological failure rate will be more than $50 \% .^{78}$

Antiretroviral medication non-compliance can result in negative clinical, immunological and virological effects. In the absence of good adherence, the immune system continues to be distracted, resulting in lower CD4 cell levels and the establishment of resistant virus strains. ${ }^{9} 10$ According to a WHO survey study in developing countries, the HIV/AIDS drug resistance rate among people starting ART ranged from $4.8 \%$ in 2007 to $6.8 \%$ in $2010 .{ }^{11}$

A considerable number of ART patients struggle to maintain a high level of adherence. According to previous studies, $12 \%-50 \%$ of HIV-positive patients do not attain adequate adherence. ${ }^{12} \mathrm{~A}$ study conducted in rural Tanzania showed that $70 \%$ of the participants achieved the desired level of adherence. ${ }^{13}$ In Soweto, South Africa, $88 \%$ of patients report more than $95 \%$ adherence rate, and the main reasons given for missing doses were being away from home $(30 \%)$, difficulty with the daily routine $(23 \%)$ and running out of pills $(12 \%) .^{14}$

A study done in Addis Ababa city describes that among patients on ART drugs, $73.3 \%$ of participants had an optimal level of adherence. Stigma, discrimination and poor relationship with healthcare providers were predictors for a suboptimal level of adherence. ${ }^{15}$

Social and economic difficulties, the healthcare policies, disease traits, disease therapies and patient-related factors are all potential impediments to patients complying with treatment plans. ${ }^{16}$

Fear of disclosure, concurrent substance abuse, forgetfulness, suspicions of treatment, overly complicated regimens, number of pills required, decreased quality of life, work and family responsibilities, falling asleep and access to medication were all identified as obstacles to adherence in a systematic review study. ${ }^{17}$

Now, countries devised a comprehensive plan to address HIV/AIDS prevention and care. This is in line with the three 90s target set by United Nations Programme on HIV/AIDS (UNAIDS) to help end the AIDS epidemic by $2030 .{ }^{18}$ The target states that $90 \%$ of all people receiving ART will have viral suppression. The plan and strategic objectives are fruitless if adherence to HAART is not well recognised.

Currently, our world, including Ethiopia, has been struggling to prevent and control a new pandemic disease called SARS-CoV-2; thus, chronic diseases like HIV/AIDS were put aside especially in developing countries. We hypothesise that there may be suboptimal adherence to ART drugs among people living with HIV (PLHIV). Having a strategy to sustain an optimal level of adherence among PLHIV is an essential step towards ensuring treatment success. The knowledge would help to evaluate the clinical management strategies and define relevant, efficient, acceptable adherence support measures for patients within the health system. So the main purpose of this study was to determine the level of adherence and its predictors among PLHIV who have been using HAART.

Therefore, this observational study hypothesises that in the era of COVID-19, there would be suboptimal adherence to ART drugs among PLHIV/AIDS.

\section{MATERIALS AND METHODS}

\section{Study setting, design and periods}

A multicentre facility-based observational cross-sectional study was conducted from August to January 2021 in the South Gondar zone, Amhara region. South Gondar zone is divided into 19 woredas and structured with 1 general hospital and 7 primary hospitals. All of them are providing ART care and treatment for its consumer. In the zone, there are $6870 \mathrm{HIV} /$ AIDS-infected patients enrolled in ART care and treatment. In this study, four public hospitals were selected randomly which provide ART care and treatment for HIV/AIDS-infected people.

PLHIV/AIDS ( $\geq 18$ years old) receiving HAART in South Gondar zone public hospitals were the study population and the study participants were adult PLHIV/AIDS ( $\geq 18$ years old) treated as outpatients in selected public hospitals and who have been on treatment for more than a 3-month period.

\section{Eligibility criteria}

HIV/AIDS-infected people greater than or equal to 18 years of age, and PLHIV who have been on treatment for more than a 3-month period and continuing their ART during the study period were eligible for this study.

\section{Sampling technique and procedure}

The study was conducted in four randomly selected hospitals. Then, the possible number of participants in each of the hospitals of the study area was allocated proportionally based on their order of arrival. Using the eligibility criteria, each study participant was included in the study and a systematic random sampling technique (every fifth interval) was applied based on their order of arrival in the ART clinics.

\section{Explanatory variables}

Sociodemographic (age, educational status, residence, marital status), personal and family-related (disclosure of serostatus, stigma and discrimination, use of complementary medicine), medication-related (drug other than antiretroviral, patients on ART, missed scheduled clinical visit), clinical (patients on tuberculosis (TB) treatment) and immunological factors (recent CD4 count, WHO clinical stage) were included in the regression analysis.

\section{Data collection instruments}

The data collection tool was adapted from two main sources. First was a questionnaire from AIDS Clinical Trial Groups ${ }^{12}$ 
adherence instrument which measured level of adherence based on patient self-report. Second was a questionnaire from the Community Programs for Clinical Research on AIDS $^{19}$ that was used to collect other information including the clinical aspect of the patient. Taking all ARTs at a right time in the week before the study was a cut-off value to consider optimal adherence to the ART medication. Otherwise, it is categorised as non-adherent. If they report missed doses during the last 7 days, the questionnaire asks a range of multiple-choice questions about why they miss their daily dose. Patients' clinical data such as WHO clinical stage and the CD4 counts were extracted from their medical records at the ART clinic by using a checklist which was adapted from different literature. Data collection was performed by five diploma nurses (supervised by three BSc nurses). A 2-day comprehensive training was given for data collectors and supervisors.

The questionnaire was compiled in English and evaluated by experts who had expertise in AIDS care and treatment situations in our country. Five AIDS experts were invited to review the Amharic version (local language) of the questionnaire for face validity and readability. The questionnaire was pilot tested on 30 (5\% of the sample) HIV-infected people. It was reported reliable and valid with Cronbach's $\alpha=0.83$, shows high level of internal consistency, $85 \%$ general interobserver agreement, $78 \%$ sensitivity and 95\% specificity, so it had been appropriate and easy to understand by participants. Data collectors were trained to have a common understanding of the objective and the methodology of the research. The investigators closely supervised the performance of the data collectors daily.

\section{Operational definition}

Good (optimal) adherence

Good (optimal) adherence means taking all ARTs in a correctly prescribed dose in the 1 week before the study. ${ }^{20}$

\section{Sample size calculation}

The sample size in this cross-sectional study was determined using a single proportion formula: $\mathrm{n}=(\mathrm{Z} 2)^{2} \mathrm{pq} / \mathrm{d}^{2}$. The minimum sample size required for the study was estimated to be 432 using the above formula where $\mathrm{n}$ is the sample size, $\mathrm{Z}$ is the standard normal deviate set at 1.96 (for $95 \%$ confidence level), d margin of error acceptable or measure of precision (taken as 0.035 ) and $\mathrm{p}=85.3 \%$ taken from the previous study ${ }^{21}$ and sample size adjusted by $10 \%$ non-response.

\section{Statistical analysis}

Data entry and analysis were done by using Epi Info V.7.1 and SPSS V.23, respectively. We have computed the frequencies and percentages of different variables for description as appropriate. Using $\mathrm{X}^{2}$ test, bivariate analysis of variables was completed with OR at $95 \%$ CI to assess the presence and degree of association between the dependent and independent variables. We hypothesise that there would be suboptimal adherence to ART drugs among PLHIV so a one-tailed p value was applied.
Table 1 Demographic and economic characteristics of the study participants in South Gondar zone, 1 August 2020-31 January $2021(n=432)$

\begin{tabular}{lcc}
\hline Variables & $\begin{array}{l}\text { Frequency } \\
(\mathbf{n = 4 3 2})\end{array}$ & Percentage \\
\hline Sex & & \\
$\quad$ Male & 172 & 39.8 \\
\hline Female & 260 & 60.2 \\
\hline Place of residence & & \\
\hline Urban & 335 & 77.5 \\
\hline Rural & 97 & 22.5 \\
\hline Age & & \\
\hline 18-24 & 103 & 23.8 \\
\hline $25-34$ & 217 & 50.2 \\
\hline 35-45 & 70 & 16.3 \\
\hline >45 & 42 & 9.7 \\
\hline Monthly income & & \\
\hline$<1000$ & 79 & 18.3 \\
\hline$\geq 1000$ & 353 & 81.7 \\
\hline Educational status & & \\
\hline Primary level of education & 55 & 12.7 \\
\hline Secondary level of education & 314 & 72.7 \\
\hline College and above & 63 & 14.6 \\
\hline
\end{tabular}

To control possible confounding variables, explanatory variables associated with outcome variables with $\mathrm{p}<0.2$ were entered into multivariable logistic regression analysis. Statistically significant associated factors were identified based on a $p$ value of $<0.05$.

\section{Patient and public involvement}

Members of the public were not involved in the study concept or design.

\section{RESULTS}

\section{Demographic and economic characteristics}

A total of 432 HIV/AIDS-infected patients who reported using ART were interviewed about adherence to their medication, giving a response rate of $100 \%$. The population consists of $172(39.8 \%)$ male and 260 female $(60.2 \%)$ patients, and $335(77.5 \%)$ were urban residents. Out of the total population, $217(50.2 \%)$ were in the age group between 25 and 34 years, and the mean age of study participants was $30.6 \pm 8$ years. The majority of participants $(322,74.5 \%)$ were married. From the total population, $211(48.8 \%)$ participants were government employees and the majority of patients' monthly income was more than or equal to 1000 Ethiopian birr (table 1).

\section{Family and clinical-related characteristics}

Out of the total population, 255 (59\%) patients disclose their serostatus. From the overall population, 45 (10.4\%) participants were stigmatised and/or discriminated by 
Table 2 Family and clinical-related characteristics of the study participants in South Gondar zone, 1 August 2020-31 January $2021(n=432)$

\begin{tabular}{lcc}
\hline Variables & Frequency $(\mathbf{n = 4 3 2 )}$ & Percentage \\
\hline Serostatus of sexual partner & \\
Positive & 226 & 52.3 \\
Negative & 17 & 3.9 \\
Unknown & 189 & 43.7 \\
Disclosure status & & \\
Not disclosed & 177 & 41 \\
Disclosed & 255 & 59
\end{tabular}

To whom serostatus disclosed

$\begin{array}{lrr}\text { Family } & 79 & 31 \\ \text { Sexual partner } & 173 & 68.2 \\ \text { Friend } & 3 & 0.8\end{array}$

Stigma and discrimination

\begin{tabular}{|c|c|c|}
\hline No & 387 & 89.6 \\
\hline Yes & 45 & 10.4 \\
\hline \multicolumn{3}{|c|}{ Do you use complementary medicine? } \\
\hline No & 351 & 81.3 \\
\hline Yes & 81 & 18.8 \\
\hline \multicolumn{3}{|c|}{ Do you use a reminder? } \\
\hline No & 40 & 9.3 \\
\hline Yes & 392 & 90.7 \\
\hline \multicolumn{3}{|l|}{ Baseline CD4 count } \\
\hline$\leq 500$ cells $/ \mathrm{mm}^{3}$ & 51 & 13.2 \\
\hline$>500$ cells $/ \mathrm{mm}^{3}$ & 336 & 86.8 \\
\hline \multicolumn{3}{|l|}{ Treatment regimens } \\
\hline TDF+3TC+EFV & 259 & 60.0 \\
\hline $\mathrm{AZT}+3 \mathrm{TC}+\mathrm{EFV}$ & 143 & 33.1 \\
\hline $\mathrm{AZT}+3 \mathrm{TC}+\mathrm{NVP}$ & 30 & 6.9 \\
\hline TDF+3 TC+EFV & 259 & 60.0 \\
\hline \multicolumn{3}{|c|}{ WHO clinical disease stage during initiation of ART } \\
\hline Stage I & 50 & 11.6 \\
\hline Stage II & 352 & 81.5 \\
\hline Stage III & 30 & 6.9 \\
\hline \multicolumn{3}{|l|}{ Recent CD4 count } \\
\hline$\leq 500$ cells $/ \mathrm{mm}^{3}$ & 87 & 20.1 \\
\hline$>500$ cells $/ \mathrm{mm}^{3}$ & 341 & 78.9 \\
\hline
\end{tabular}

ART, antiretroviral therapy; AZT, Zidovudine; EFV, Efavirenz; NVP, Nevirapine; 3TC, Lamivudine; TDF, Tenofovir.

their family, friends or community. Again, 81 (18.8\%) were using traditional medicine in addition to their ART drugs. Regular mealtimes $(193,44.7 \%)$ was the most common reminder (table 2).

\section{Adherence and healthcare service characteristics}

Based on the patient's self-report, $81.5 \%$ (95\% CI: $78 \%$ to $85.2 \%$ ) of participants had optimal adherence level (take
Table 3 Adherence and healthcare service-related characteristics of the study participants in South Gondar zone, 1 August 2020-31 January $2021(n=432)$

\begin{tabular}{|c|c|c|}
\hline Variables & $\begin{array}{l}\text { Frequency } \\
(n=432)\end{array}$ & Percentage \\
\hline \multicolumn{3}{|c|}{ Do you miss your dose in the last 7 days? } \\
\hline No & 352 & 81.5 \\
\hline Yes & 80 & 18.5 \\
\hline \multicolumn{3}{|l|}{ Number of missed doses } \\
\hline $1-2$ & 57 & 13.2 \\
\hline $3-4$ & 23 & 5.3 \\
\hline \multicolumn{3}{|c|}{ Reason for missing taking ART medication } \\
\hline Away from home & 19 & 23.75 \\
\hline Forgot about it & 31 & 38.75 \\
\hline Busy with other things & 12 & 15 \\
\hline Sickness & 18 & 22.5 \\
\hline \multicolumn{3}{|c|}{ Missed scheduled clinical visit } \\
\hline No & 386 & 89.4 \\
\hline Yes & 46 & 10.6 \\
\hline \multicolumn{3}{|c|}{ Do you take drugs other than ARV? } \\
\hline No & 328 & 75.9 \\
\hline Yes & 104 & 24.1 \\
\hline
\end{tabular}

$\mathrm{ART}$, antiretroviral therapy; ARV, antiretroviral.

their entire daily dose) 1 week before the interview. The reasons given for missing their treatment were forgetting about it $(31,7.1 \%)$ and being away from home (19, $4.4 \%)$. Only $46(10.6 \%)$ of study participants missed the scheduled clinical visit and $104(24.1 \%)$ patients were taking drugs other than their ART medicine (table 3).

\section{Factors associated with adherence to ART}

Stigmatised or discriminated patients were $60 \%$ less likely to adhere to ART compared with non-stigmatised and non-discriminated patients (adjusted OR $(\mathrm{AOR})=0.4$, 95\% CI (0.2 to 0.84)). Patients who missed scheduled clinical visits were $55 \%$ less likely to adhere to their ART compared with patients who did not miss scheduled clinical visits, $55 \%$ (AOR=0.45 (0.21 to 0.94)). Patients who had been on TB treatment have been $55 \%$ less likely to adhere to ART compared with patients who had not been on TB treatment $(\mathrm{AOR}=0.45$ (0.24 to 0.83$))$. Respondents whose recent $\mathrm{CD} 4$ cell count was less than 500 cells $/ \mathrm{mm}^{3}$ were $70 \%$ less likely to adhere to treatment compared with respondents whose $\mathrm{CD} 4$ count was greater than 500 cells $/ \mathrm{mm}^{3}$ (AOR=0.3 (0.14 to 0.73)). Patients in WHO clinical stage III at the time of ART initiation were $76 \%$ less adherent to ART compared with their counterpart $(\mathrm{AOR}=0.24(0.098$ to 0.57$))$ (table 4$)$. 
Table 4 Factors associated with ART adherence among adult patients on ART in public health institutions in South Gondar zone, 1 August 2020-31 January 2021

\begin{tabular}{|c|c|c|c|c|c|}
\hline & \multicolumn{2}{|c|}{ Adherence to ARV } & \multirow[b]{2}{*}{ COR $(95 \% \mathrm{Cl})$} & \multirow[b]{2}{*}{ AOR $(95 \% \mathrm{Cl})$} & \multirow[b]{2}{*}{$P$ value } \\
\hline & Adherent & Non-adherent & & & \\
\hline \multicolumn{6}{|c|}{ Drug other than ARV } \\
\hline No & 275 & 53 & 1 & 1 & \\
\hline Yes & 77 & 27 & 0.55 (0.3 to 0.9$)$ & 1.14 (0.53 to 2.45$)$ & \\
\hline \multicolumn{6}{|c|}{ Stigmatised and discriminated patients on ART } \\
\hline No & 326 & 61 & 1 & 1 & \\
\hline Yes & 26 & 16 & $0.26(0.13$ to 0.5$)$ & $0.4(0.2$ to 0.84$)$ & 0.016 \\
\hline \multicolumn{6}{|c|}{ Missed scheduled clinical visit } \\
\hline No & 325 & 61 & 1 & 1 & \\
\hline Yes & 27 & 19 & $0.27(0.14$ to 0.51$)$ & $0.45(0.21$ to 0.94$)$ & 0.034 \\
\hline \multicolumn{6}{|c|}{ Patients on TB treatment } \\
\hline No & 297 & 50 & 1 & 1 & \\
\hline Yes & 55 & 30 & 0.41 (0.18 to 0.53$)$ & 0.45 (0.24 to 0.83$)$ & 0.01 \\
\hline \multicolumn{6}{|l|}{ Recent CD4 count } \\
\hline$\geq 500$ cells $/ \mathrm{mm}^{3}$ & 328 & 65 & 1 & 1 & 0.023 \\
\hline$<500$ cells $/ \mathrm{mm}^{3}$ & 27 & 17 & $0.23(0.12$ to 0.56$)$ & $0.3(0.14$ to 0.73$)$ & 0.007 \\
\hline \multicolumn{6}{|c|}{ WHO clinical stage at the time of ART initiation } \\
\hline Stage I & 42 & 8 & 1 & & \\
\hline Stage II & 291 & 61 & 0.208 (0.68 to 0.633 ) & & \\
\hline Stage III & 12 & 11 & 0.23 (0.1 to 0.55$)$ & 0.24 (0.098 to 0.57$)$ & 0.027 \\
\hline
\end{tabular}

AOR, adjusted OR; ART, antiretroviral therapy; ARV, antiretroviral; TB, tuberculosis.

\section{DISCUSSION}

This study was focused on the magnitude of optimal ART drug adherence and associated factors for a low level of adherence among HIV/AIDS-infected patients at public hospitals in the South Gondar zone. The study found that $81.5 \%$ of participants were having an optimal adherence based on a 1-week recall before the actual interview. This is far less than the finding in Southwest Ethiopia where $95 \%$ of patients had optimal adherence to their prescribed doses ${ }^{22}$ and similarly, in Northeast Ethiopia, 95\% of patients also had optimal adherence to their medication. ${ }^{23}$ However, our findings were comparably higher than those found in Tanzania, where only $70 \%$ of the participants achieved the desired level of adherence. ${ }^{13}$ Another study conducted in Northeastern Ethiopia explains that the level of optimal adherence was found to be $71.8 \%$ in the past 7 days of recall of their daily doses. ${ }^{24}$ But it is almost consistent with a study finding in Addis Ababa reporting $82.8 \%$ of patients had optimal adherence. $^{25}$

Stigmatised or discriminated patients were $60 \%$ (AOR $=0.4,95 \%$ CI $(0.2$ to 0.84$)$ ) less likely to adhere to ART compared with their counterparts. Stigma and discrimination, especially in sub-Saharan Africa, play the main role for poor patient follow-up in treatment care and extensive contribution for inadequate HIV/ AIDS prevention. ${ }^{26}$ Patients frequently skipped doses due to fear of being identified as HIV positive. A systematic review of 26715 HIV-positive people in 32 countries discovered that HIV-related stigma hampered adherence to ART, principally through impairing social support and adaptive measures taken to manage stigma during medication. The study highlights the relevance of social relationships in improving adherence, particularly in resource-constrained contexts, and highlights the importance of social integration in HIV-positive people's treatment experiences. ${ }^{27}$

Patients who had been on TB treatment are $55 \%$ less likely to adhere to ART compared with patients who did not have $\mathrm{TB}$ treatment $(\mathrm{AOR}=0.45 \quad(0.24$ to 0.83$))$. A cross-sectional study found that individuals who had been on TB treatment in addition to ART drugs have a high level of ART non-adherence. ${ }^{28}$ Patients more frequently adhered to TB treatment compared with ART. This might be due to the shorter duration of TB treatment compared with life-long ART medication. Another possible reason was that patients prioritise TB treatment and would have less attention to life-long ART medication to avoid the burden of medications. ${ }^{29}$

Respondents whose recent CD4 count less than 500 cells $/ \mathrm{mm}^{3}$ were $70 \%$ less likely to adhere to treatment compared with respondents whose $\mathrm{CD} 4$ count was greater than 500 cells $/ \mathrm{mm}^{3}$ (AOR=0.3 (0.14 to 0.73)). A study finding shows that optimal level of adherence was 
found to be a key factor in virological and immunological results. A CD4 cell count was increased by 179, 159, and 53 cells $/ \mathrm{mm}^{3}$ in the groups who had $100 \%, 80 \%-99 \%$, and $0 \%-79 \%$ level of adherence, respectively. ${ }^{30} \mathrm{~A}$ study conducted in a developing nation found that patients with CD4 counts below 200 cells $/ \mathrm{mm}^{3}$ had nearly five times higher chance of treatment failure than those with CD4 counts above 200 cells $/ \mathrm{mm}^{3}{ }^{31}$ Viral replication reduces when CD4 cell count rises, implying that viral burden is inversely proportional to $\mathrm{CD} 4$ cell count. When compared with immune-competent patients with HIV infection, patients with deteriorated immune status had raised viral load. Furthermore, individuals with weakened immunity are more vulnerable to a variety of opportunistic illnesses, which make them suffer from the vicious cycle of immune depletion and viral replication. ${ }^{32}$

Patients who had been on WHO clinical stage III at the time of ART initiation were $76 \%$ less adherent to ART compared with their counterparts. It has been proven that HAART is effective in suppressing HIV replication, decreasing morbidity and mortality associated with HIV, suppressing development and spread of ART drugresistant HIV, and improving quality of life in adults as well as children infected with HIV. However, drugs do not work in patients who do not take them properly so optimal adherence to HAART is a crucial step towards the successful outcome of therapy. ${ }^{78}$

Poor adherence has several effects on patients' health. Some of them severely compromise the effectiveness of treatment, making this a critical issue in the population health from the perspective of quality of health and health economics. So there should be an intervention aimed at improving adherence because it has a significant positive return on patients' health through primary prevention and control of adverse outcomes. ${ }^{33}$

Using the health belief model, further exploration is important to identify the possible trigger that enforces adherence behaviour. The health belief model helps to have deep insight on the consequences of nonadherence to ART, the personal risk of problems about medication non-adherence, the value of adhering to ART drugs and the obstacles for not taking ART medication.

The limitation of this study was the measurement of adherence is based on PLHIV self-reports of missed doses which may be subject to social desirability and recall biases. Findings are also generalisable only for patients treated as outpatients; it excludes patients treated at the inpatient level. This condition may limit to conclude inpatient treated PLHIV/AIDS. Since the study was conducted during the COVID-19 pandemic, the actual magnitude of optimal adherence may not be similar to our finding. As this is a cross-sectional study, cause-effect relation could not be analysed. Despite these limitations, our study demonstrates strengths. One of the strengths was it was conducted using two standardised and sounded adherence measurement tools which helped in ensuring the quality of the study.

\section{CONCLUSIONS}

Stigma or discrimination, missing scheduled clinical visits, being on anti-TB treatment, recent CD4 cell count less than 500 cells $/ \mathrm{mm}^{3}$ and patients in WHO clinical stage III at the time of ART initiation were factors associated with a low level of adherence to ART drugs. The establishment of a monitoring and evaluation system during clinical visits helps to achieve optimal adherence. Maintaining relatively high $\mathrm{CD} 4$ cell counts during HAART encourages patients on ART to have optimal adherence; again, this reduces disease severity. The intervention targeted to reduce discrimination, counselling before initiation of treatment and educational therapy during follow-up is advised to have maximum effect on improving ART adherence.

Acknowledgements We would like to express our gratitude to South Gondar zone HIV/AIDS Prevention and Control Office. We are also grateful to the data collectors and professionals working in the ART clinic for facilitating the data collection.

Contributors SBZ conceived the research project, supervised the data collection process, conducts the analysis, write-up and review of literature. TMA collected the data, helped with the analysis of data and statistics. All authors agreed the final version to be published and are responsible for all aspects of the work.

Funding The authors have not declared a specific grant for this research from any funding agency in the public, commercial or not-for-profit sectors.

Competing interests None declared.

Patient and public involvement Patients and/or the public were not involved in the design, or conduct, or reporting, or dissemination plans of this research.

Patient consent for publication Not required.

Ethics approval An ethical approval letter was obtained from the Institutional Review Board of Wollo University College of Medicine and Health Sciences (no: 0156/CMHS/IRB/2020). Official permission letter was obtained from the South Gondar zone health department and each hospital.

Provenance and peer review Not commissioned; externally peer reviewed.

Data availability statement Data are available upon reasonable request. Not applicable.

Open access This is an open access article distributed in accordance with the Creative Commons Attribution Non Commercial (CC BY-NC 4.0) license, which permits others to distribute, remix, adapt, build upon this work non-commercially, and license their derivative works on different terms, provided the original work is properly cited, appropriate credit is given, any changes made indicated, and the use is non-commercial. See: http://creativecommons.org/licenses/by-nc/4.0/.

ORCID iD

Shimeles Biru Zewude http://orcid.org/0000-0003-3507-9612

\section{REFERENCES}

1 UNAIDS. Global HIVIAIDS statistics-fact sheet, 2020.

2 Ramos AN, Matida LH, Hearst N, et al. Aids in Brazilian children: history, surveillance, antiretroviral therapy, and epidemiologic transition, 1984-2008. AIDS Patient Care STDS 2011;25:245-55.

3 Wubshet M, Berhane Y, Worku A, et al. High loss to follow-up and early mortality create a substantial reduction in patient retention in antiretroviral treatment programs in Northwest Ethiopia. Isrn AIDS 2012.

4 UNAIDS and World Health Organization. Global HIV/AIDS response: epidemic update and health sector progress towards universal access: progress report 2011. Global HIV/AIDS response: epidemic update and health sector progress towards universal access: progress report 2011.

5 Paterson DL, Swindells S, Mohr J, et al. Adherence to protease inhibitor therapy and outcomes in patients with HIV infection. Ann Intern Med 2000;133:21-30.

6 Deleuze J, Sicard D, Coste J. Enquête SUR I'observance des traitements antirétroviraux comportant un inhibiteur de protéase 
CheZ les patients infectés par le VIH. Annales de médecine interne 2000.

7 HIV/AIDS Prevention and Control Office. Guidelines for pediatric HIVIAIDS care and treatment in Ethiopia. Addis Ababa: HIV/AIDS Prevention and Control Office, 2008.

8 Shah CA. Adherence to high activity antiretrovial therapy (HAART) in pediatric patients infected with HIV: issues and interventions. Indian J Pediatr 2007;74:55-60.

9 Esteban Gómez MJ, Escobar Rodríguez I, Vicario Zubizarreta MJ, et al. [Influence of antiretroviral therapy characteristics on pediatric patient adherence]. Farm Hosp 2004;28:34-9.

10 Malee K, Williams P, Montepiedra G, et al. Medication adherence in children and adolescents with HIV infection: associations with behavioral impairment. AIDS Patient Care STDS 2011;25:191-200.

11 World Health Organization. The HIV drug resistance report. Geneva; Switzerland, 2012.

12 Chesney MA, Ickovics JR, Chambers DB, et al. Self-reported adherence to antiretroviral medications among participants in HIV clinical trials: the AACTG adherence instruments. AIDS Care 2000;12:255-66

13 Nyogea D, Mtenga S, Henning L, et al. Determinants of antiretroviral adherence among HIV positive children and teenagers in rural Tanzania: a mixed methods study. BMC Infect Dis 2015;15:28.

14 Nachega JB, Stein DM, Lehman DA, et al. Adherence to antiretroviral therapy in HIV-infected adults in Soweto, South Africa. AIDS Res Hum Retroviruses 2004;20:1053-6.

15 Mengistu Z, Chere A. Adherence to antiretroviral therapy and its associated factors among people living with HIV/AIDS in Addis Ababa, Ethiopia. Ethiop Med J 2012:50:355-61.

16 Vitoria M, Vella S, Ford N. Scaling up antiretroviral therapy in resource-limited settings: adapting guidance to meet the challenges. Curr Opin HIV AIDS 2013;8:12-18.

17 Mills EJ, Nachega JB, Buchan I, et al. Adherence to antiretroviral therapy in sub-Saharan Africa and North America: a meta-analysis. JAMA 2006;296:679-90.

18 UNAIDS. 90-90-90 - An ambitious treatment target to help end the AIDS epidemic 2017.

19 Mannheimer S, Friedland G, Matts J, et al. The consistency of adherence to antiretroviral therapy predicts biologic outcomes for human immunodeficiency virus-infected persons in clinical trials. Clin Infect Dis 2002;34:1115-21.

20 Letta S, Demissie A, Oljira L, et al. Factors associated with adherence to antiretroviral therapy (art) among adult people living with HIV and attending their clinical care, eastern Ethiopia. BMC Int Health Hum Rights 2015;15:1-7.
21 Tadesse S, Tadesse A, Wubshet M. Adherence to antiretroviral treatment and associated factors among people living with HIV/AIDS in Northwest Ethiopia. J Trop Dis 2014;2:2.

22 Tiyou A, Belachew T, Alemseged F, et al. Predictors of adherence to antiretroviral therapy among people living with HIV/AIDS in resource-limited setting of Southwest Ethiopia. AIDS Res Ther 2010;7:1-0.

23 Ketema AK, Weret ZS. Assessment of adherence to highly active antiretroviral therapy and associated factors among people living with HIV at Debre Berhan referral hospital and health center, northeast Ethiopia: a cross-sectional study. HIVIAIDS 2015;7:75.

24 Legesse TA, Reta MA. Adherence to antiretroviral therapy and associated factors among people living with HIV/AIDS in Hara town and its surroundings, north-eastern Ethiopia: a cross-sectional study. Ethiop J Health Sci 2019;29:299-308.

25 Awel M. Antiretroviral adherence, and its detriments among people living with HIV/AIDS on highly active antiretroviral therapy in two hospitals of Oromiya regional state. Ethiopia. Ethiopian public health association (EPHA) extract from EPHA - sponsored master thesis on HIV/AIDS 2008;4: :9-19.

26 Maman S, Abler L, Parker L, et al. A comparison of HIV stigma and discrimination in five international sites: the influence of care and treatment resources in high prevalence settings. Soc Sci Med 2009;68:2271-8.

27 Katz IT, Ryu AE, Onuegbu AG, et al. Impact of HIV-related stigma on treatment adherence: systematic review and meta-synthesis. J Int AIDS Soc 2013;16:18640.

28 Monjok E, Smesny A, Okokon IB, et al. Adherence to antiretroviral therapy in Nigeria: an overview of research studies and implications for policy and practice. Hiv Aids 2010;2:69.

29 Zinski A, Westfall AO, Gardner LI, et al. The contribution of missed clinic visits to disparities in HIV viral load outcomes. Am J Public Health 2015;105:2068-75

30 Hogg RS, Heath K, Bangsberg D, et al. Intermittent use of triplecombination therapy is predictive of mortality at baseline and after 1 year of follow-up. AIDS 2002;16:1051-8.

31 Lailulo $\mathrm{Y}$, Kitenge M, Jaffer S, et al. Factors associated with antiretroviral treatment failure among people living with HIV on antiretroviral therapy in resource-poor settings: a systematic review and metaanalysis. Syst Rev 2020;9:1-7.

32 Mills EJ, Nachega JB, Bangsberg DR, et al. Adherence to HAART: a systematic review of developed and developing nation patientreported barriers and facilitators. PLoS Med 2006;3:e438.

33 UNAIDS. AIDS by the numbers 2015. Geneva Switzerland: UNAIDS, 2015. 